\title{
Breast density and mode of detection in relation to breast cancer specific survival: a cohort study
}

Åsa Olsson ${ }^{1 *}$, Hanna Sartor ${ }^{2}$, Signe Borgquist ${ }^{3}$, Sophia Zackrisson ${ }^{4}$ and Jonas Manjer ${ }^{1,4}$

\begin{abstract}
Background: The aim of this study was to examine breast density in relation to breast cancer specific survival and to assess if this potential association was modified by mode of detection. An additional aim was to study whether the established association between mode of detection and survival is modified by breast density.

Methods: The study included 619 cases from a prospective cohort, The Malmö Diet and Cancer Study. Breast density estimated qualitatively, was analyzed in relation to breast cancer death, in non-symptomatic and symptomatic women, using Cox regression calculating hazard ratios (HR) with 95\% confidence intervals. Adjustments were made in several steps for; diagnostic age, tumour size, axillary lymph node involvement, grade, hormone receptor status, body mass index (baseline), diagnostic period, use of hormone replacement therapy at diagnosis and mode of detection. Detection mode in relation to survival was analyzed stratified for breast density. Differences in HR following different adjustments were analyzed by Freedmans\%.
\end{abstract}

Results: After adjustment for age and other prognostic factors, women with dense, as compared to fatty breasts, had an increased risk of breast cancer death, HR 2.56:1.07-6.11, with a statistically significant trend over density categories, $p=0.04$. In the stratified analysis, the effect was less pronounced in non-symptomatic women, HR 2.04:0.49-8.49 as compared to symptomatic, HR 3.40:1.06-10.90. In the unadjusted model, symptomatic women had a higher risk of breast cancer death, regardless of breast density. Analyzed by Freedmans\%, age, tumour size, lymph nodes, grade, diagnostic period, ER and PgR explained 55.5\% of the observed differences in mortality between non-symptomatic and symptomatic cases. Additional adjustment for breast density caused only a minor change.

Conclusions: High breast density at diagnosis may be associated with decreased breast cancer survival. This association appears to be stronger in women with symptomatic cancers but breast density could not explain differences in survival according to detection mode.

\section{Background}

High breast density is an independent risk factor for breast cancer [1] but also decreases the sensitivity [2-4] for tumour detection by mammography [2-5].

The concept of breast density is based on the radiological appearance of the breast parenchyma and denser breasts have a higher proportion of epithelial and connective tissue in relation to fat, while non-dense breasts are richer in fat [6,7]. Breast density decreases after menopause [8] and with increasing body mass index (BMI) [9-11]. It has also been related to hormonal factors such as menopausal status and use of hormone replacement

\footnotetext{
* Correspondence: asa.olsson@skane.se

'Department of Surgery, Lund University, Skåne University Hospital, SE- 205 02 Malmö, Sweden

Full list of author information is available at the end of the article
}

therapy (HRT) $[8,11,12]$, but the biological mechanism connecting breast density to breast cancer risk is not clearly understood.

In order to increase sensitivity, shorter screening intervals have been suggested for younger women and/or women with denser breasts [13]. However, the effect of such interventions regarding mortality, or the potential effect of breast density on survival per se, is not known.

Six studies, have reported on breast density in relation to breast cancer specific survival. Two of the studies found that women with dense breasts had a slightly impaired survival $[5,14]$, one found a statistically significant better survival in women with dense breasts [4], and two studies found no association at all $[15,16]$. In one study, breast density was associated with poorer survival only in women not receiving radiotherapy [17]. Women with screening

\section{Biomed Central}


detected breast tumours have a better prognosis compared to women with clinically diagnosed breast cancer, despite adjustment for stage at diagnosis and other tumour characteristics [18-21]. The prognostic advantage associated with mammography screening could be less evident in women with denser breasts, given the lower mammographic sensitivity. If breast density has an independent effect on survival, breast density would affect outcome regardless of detection mode, and might explain part of the survival difference between women with non-symptomatic vs. symptomatic tumours.

The aim of this study was to examine breast density in relation to survival following breast cancer diagnosis, using breast cancer specific death as the endpoint and to assess if this potential association was modified by mode of detection. An additional aim was to examine whether the established association between mode of detection and survival is modified by breast density.

\section{Methods}

\section{The Malmö Diet and Cancer Study}

The Malmö Diet and Cancer Study (MDCS) is a population based, prospective cohort study inviting residents in Malmö, Sweden, born between 1923 and 1950. Between 1991-1996, 17035 women were enrolled, corresponding to a participation rate of approximately $40 \%$. The study includes questionnaires and interviews on diet, medications, socio-economy and life-style factors [22,23]. Blood samples and information on weight and height were collected at baseline, and BMI was calculated as $\mathrm{kg} / \mathrm{m}^{2}[22,23]$.

\section{Identification of breast cancer patients}

Data on cancer events in the MDCS-population has been retrieved from the Swedish Cancer Registry and The Regional Tumour Registry for Southern Sweden. Until 31 Dec. 2007, 826 incident breast cancer cases were diagnosed. Women with prevalent breast cancer at baseline ( $\mathrm{n}=576)$ were excluded. Participants in the Malmö Diet and Cancer Study have all given written informed consent at baseline. Through subsequent advertisements, included women have been informed about planned additional analyses and about the possibilities of withdrawal. No new contacts have been taken with included women or their relatives for this particular study. The present study was approved by The Ethical Committee at Lund University (Dnr 652/2005 and Dnr 166/2007).

\section{Screening status}

This study included women from the MDCS cohort, potentially exposed to mammography screening. The general screening service started in Malmö in 1990 and was, during the study period, inviting women 50-69 years of age but with an extension of the upper age-limit to 74 years during the last decade. Women were invited at
18 or 24 months intervals depending on parenchymal pattern, (the shorter interval for women with denser breasts) [24]. Since there was no information on the presence of breast implants, or the use of opportunistic screening among participants in the general screening program, we refer to this group as non-symptomatic cancers. Mammography, and opportunistic screening, has to some extent been available outside the general screening program. Out of the final study population $(n=619$, see below), 30 women were considered as diagnosed by screening outside general screening and they were classified as non-symptomatic if clearly stated in the clinical notes that they were asymptomatic at the time of the diagnostic mammogram. No information on screening intervals was available for this group. The diagnostic ages in women with non-symptomatic cancers ranged from 48 to 81 years, which were the limits used to define the present study population. An interval cancer was defined as a symptomatic breast cancer, diagnosed clinically within 18 or 24 months, (depending on the planned screening interval), from a previously normal screening mammogram.

\section{Study population}

Out of 826 incident breast cancer cases, 79 cases with cancer in situ were excluded as the primary objective of the present study was to investigate survival. Fifteen cases with bilateral tumours were excluded due to the difficulty to retrospectively evaluate the stage of these tumours. Women with unknown screening status $(n=19)$ and unknown breast density $(n=36)$ were also excluded. Finally, 65 women were excluded due to insufficient amounts of tumour tissue. A single woman could be excluded for several reasons. Adding the age criteria 48-81 years for nonsymptomatic cancers, the final study population included 619 cases. Out of these 619 women, 350 were nonsymptomatic, 177 were symptomatic and 87 were interval cancers. In another five symptomatic women diagnosed clinically, it was not possible to exclude the possibility of an interval cancer. These women were included as "symptomatic" in analyses using two categories of detection mode (non-symptomatic/symptomatic) and as "unknown" in analyses using three categories (non-symptomatic/inter$\mathrm{val} /$ symptomatic). The eighteen year period of inclusion was divided into three six-year categories to define diagnostic period.

\section{Follow-up}

Information on cause of death and vital status was retrieved from the Swedish Causes of Death Registry, with last follow up 31 Dec. 2010 [25]. At the end of follow up, 76 women had died from breast cancer as underlying or contributing cause of death (mean age at death: 70.1 years; standard deviation (SD): 8.6). Forty-seven women had died from other causes (mean age at death: 73.9 years; SD: 6.6). 
Median follow-up from diagnosis to death, end of followup or emigration ( 2 women) was 7.8 years (range $0.5-19.1$ ).

\section{Tumour and patient characteristics}

Information on tumour size, axillary lymph node involvement (ALNI), type of surgery, planned adjuvant therapy, menopausal status and use of HRT at diagnosis was collected from medical journals, including pathology reports. Fifty-eight women had not been operated in the axilla and thus had missing information on ALNI. In most of these cases, an axillary dissection had been considered unnecessary at the pre-operative evaluation and they were classified as ALNI negative. All these women had a tumour size less than or equal to $20 \mathrm{~mm}$, and were free from distant metastases at diagnosis. One woman with distant metastases at diagnosis, but registered as having negative lymph nodes was classified as "unknown" for ALNI. The study population included four women with distant metastases at diagnosis, one diagnosed with an interval cancer and the other three had symptomatic tumours. Three of these women had died from breast cancer at end of follow-up. Cases diagnosed from study start in 1991 and until 31 Dec 2004, were re-evaluated regarding tumour type according to the World Health Organizationclassification [26], and assessed for tumour grade according to Elston and Ellis [27] by one senior pathologist [28]. For cases diagnosed 1 Jan 2005 to 31 Dec 2007, information on tumour grade was collected from the pathology reports.

Tissue micro arrays for immunohistochemical analyses were constructed as described previously in order to define hormone receptor status; oestrogen receptor $\alpha$ (ER) and progesterone receptor (PgR) [28]. In this study, $\leq 10 \%$ or $>10 \%$ of positive nuclei defined negative and positive hormone receptor status, in accordance with clinically used limits [29].

\section{Breast density}

Breast density was estimated qualitatively and reported by experienced breast radiologists at the initial evaluation of the diagnostic mammogram. In the assessment of women recalled from screening with suspicion of breast cancer, the screening mammogram (craniocaudal and mediolateral oblique views) was completed with as many views as needed, corresponding to a diagnostic mammography examination with at least three views. Thus, the assessment of breast density was done at the time of the diagnostic work-up and not at the screening readings. Breast density was measured using both breasts and all views, although when there was an apparent effect of the tumor on the surrounding tissue in terms of higher breast density, the contralateral view was used. When breast density differed between breasts, not related to the tumour, the breast with the highest breast density was used for final decision. Information on breast density was missing in about one third of cases, and these mammograms were retrospectively revised by one breast radiologist (SZ) and a trained, supervised resident in radiology (HS). In 36 women, no mammograms were possible to find for revision. At end of follow-up, 11out of these 36 women had died from breast cancer and they were excluded from the study. The mammograms at the institution were analogue up until 2003 and digital from 2004 and onwards. Routinely, during the last 30 years, a three category classification of breast density has been used: "fatty", "moderate" or "dense". This classification is a modification of the Breast Imaging Reporting and Data System (BIRADS) where "fatty" corresponds to BI-RADS 1 (almost entirely fat), "moderate" to BI-RADS $2+3$ (scattered fibroglandular densities; and heterogeneously dense) and "dense" to BI-RADS 4 (extremely dense) [30].

For the descriptive analysis of the study-population, the three density categories described above were used. In some stratified analyses, fatty breasts and moderately dense breast were combined and compared to dense breasts.

\section{Methods}

Factors related to the ability to diagnose a tumour; age, use of HRT, menopausal status and breast density at diagnosis, BMI at baseline, diagnostic period and mode of detection were compared according to outcome, defined as alive at end of follow-up, dead from breast cancer (as cause of death or contributing cause of death), or dead from other causes. Vital status and cause of death were further investigated in relation to known prognostic factors and treatment; diagnostic age, tumour size, ALNI, tumour grade, ER, PgR, type of surgery, type of lymph node examination and planned adjuvant treatment.

Factors related to the ability to diagnose a tumour were also investigated in relation to breast density. Differences were tested with ANOVA for continuous variables, and the Chi-2 test for categorical variables. All tests were twosided and a p-value $<0.05$ was considered significant.

Breast density was analysed in relation to subsequent breast cancer death using Cox proportional hazards analysis calculating hazard ratios (HR) with 95\% confidence intervals (CI). Adjustments were first made for prognostic factors; age, diagnostic period, tumour size, ALNI, grade, ER and PgR $\left(\mathrm{HR}^{2}\right)$. Additional adjustments included BMI and HRT $\left(\mathrm{HR}^{3}\right)$. The correlation between diagnostic age and menopausal status was tested using tau-b, analysing diagnostic age as a categorical variable (ten-year categories) and showed a statistically significant correlation, 0.405, $\mathrm{p}=<0.001$, which is why the adjustments did not include menopausal status. All analyses were performed separately in non-symptomatic and symptomatic cases. In a final model, analysing all subjects, adjustments were also made for detection mode $\left(\mathrm{HR}^{4}\right)$, 
and interactions between detection mode and breast density were tested using an interaction term. Linear trends over density categories were calculated yielding two-sided p-values. The association between detection mode and breast cancer death was analysed by the same model, first adjusting for prognostic factors as above $\left(\mathrm{HR}^{2}\right.$ and $\mathrm{HR}^{3}$ ), and finally, in the analysis of all subjects, also for breast density (fatty/moderate/dense). Interactions between detection mode and breast density were tested using an interaction term. Freedmans\% [31] was used to determine the contribution of these adjustments to the survival difference between non-symptomatic and symptomatic cases. Freedmans $\%$ was defined as: $100(1-\mathrm{a} / \mathrm{b})$; where $b$ is the logarithm of the unadjusted HR, and $a$, the logarithm of the adjusted HR.

The proportional hazard assumption was tested using a log minus log curve, and for all analyses on survival, the assumption was met. Missing values were included as separate categories in all multivariate analyses, thus, the adjustments made did not affect the number of included cases. All analyses were repeated excluding the four women with distant metastasis at diagnosis and all analyses were also repeated using death from causes other than breast cancer as the event and adjusted separately for age, BMI, HRT and diagnostic period as these factors are likely to affect overall mortality. A sensitivity analysis was made to the un-stratified Cox analyses, by adding adjustment for one modality of adjuvant therapy at the time (planned radio-therapy yes/no, planned chemo-therapy yes/no, planned antihormonal treatment yes/no). SPSS 20.0 was used for all calculations.

\section{Results}

Women who died from causes other than breast cancer were slightly older at baseline and at diagnosis as compared to women alive at follow-up or women who died from breast cancer, Table 1 . Few cases were pre-menopausal at diagnosis. A BMI $\geq 30$ was more common among women dead from other causes, as compared to other groups. Women who died from breast cancer had less often nonsymptomatic tumours and were somewhat more likely to have dense breasts, Table 1.

Women who died from breast cancer had larger tumours $(>20 \mathrm{~mm})$, tumours of higher grade (grade III) and were more often ALNI positive and ER- and PgR negative, as compared to women alive at follow-up, or women dead from other causes, Table 2. Extensive surgery with mastectomy and axillary lymph node dissection was also more common among women who had died from breast cancer, and this group had more often been planned for chemo- or radiotherapy, Table 2 .

Women with dense breasts were younger, more often premenopausal, HRT users and more likely to have a $\mathrm{BMI}<25$, as compared to women with fatty breasts,
Table 3. No differences were seen regarding breast density and detection mode.

High breast density was positively associated with death from breast cancer, and the HRs increased further following adjustments. There was also a dose-response pattern with a statistically significant trend over density categories in the adjusted model, including all cases, Table 4. The association between breast density and death from breast cancer was stronger among symptomatic women as compared to non-symptomatic. The p-values for interaction with mode of detection were for moderately dense breasts 0.021, and for dense breasts 0.006 . In Table 5, where mode of detection was analysed stratified for breast density (in two categories), the p-value for interaction between symptomatic tumours and dense breasts was 0.685 . However, these analyses included few events and confidence intervals were wide.

In the unadjusted model, symptomatic cases had a higher risk of breast cancer death as compared to nonsymptomatic regardless of breast density, Table 5 . The HRs were attenuated in the adjusted models, and did not reach statistical significance. Estimated by Freedmans\%, diagnostic age, tumour size, ALNI, grade, ER and PgR explained $55.6 \%$ of the observed differences in mortality between non-symptomatic and symptomatic cases. Additional adjustment for breast density caused only a minor change in Freedmans\%, +0.6 per cent units.

All results remained similar excluding women with distant metastases at diagnosis (data not shown). Women with dense, as compared to fatty breasts, had a decreased risk of death from causes other than breast cancer in the crude model including all subjects, HR: 0.42:0.20-0.91, pvalue for trend 0.03 . The HR was $0.68(0.31-1.49)$ adjusted for age at diagnosis and diagnostic period, and 0.74(0.311.73) adjusted for age, BMI, HRT and diagnostic period (Additional file 1: Table S1 and Table S2). Results were similar after adjustment for planned chemotherapy and planned anti-hormonal therapy. Adjustment for radiotherapy caused only minor changes in the results but diminished the hazard ratios slightly. In the fully adjusted models in Table 4, $\mathrm{HR}^{3}$ changed from 2.59:1.08-6.20 to 2.51:1.04-6.02 and $\mathrm{HR}^{4}$ changed from 2.66:1.11-6.38 to 2.59:1.08-6.23 for women with dense breasts. In the fully adjusted models in Table $5 \mathrm{HR}^{3}$ changed from 1.55:0.952.52 to $1.44: 0.87-2.38$ and $\mathrm{HR}^{4}$ from 1.54:0.94-2.52 to 1.45:0.88-2.40 for women with symptomatic tumours.

\section{Discussion}

In the present study high breast density was positively associated with death from breast cancer, in a dose-response pattern. Moreover, this association was most pronounced among symptomatic women. Breast density did not substantially contribute to the difference in survival between women with non-symptomatic vs. symptomatic cancers. 
Table 1 Vital status and factors potentially related to breast density and tumour detection

\begin{tabular}{|c|c|c|c|c|c|}
\hline \multirow[t]{2}{*}{ Factors } & \multirow[t]{2}{*}{ Category } & Alive $(n=496)$ & Dead breast cancer $(n=76)$ & Dead other cause $(n=47)$ & \multirow[t]{2}{*}{ All $(n=619)$} \\
\hline & & \multicolumn{3}{|c|}{ Number (column percent) Mean, SD in italics } & \\
\hline Age at baseline & Years & $56.0(6.6)$ & $58.2(7.8)$ & $61.6(6.9)$ & $56.7(7.0)$ \\
\hline Age at diagnosis & Years & $64.0(7.3)$ & $64.5(8.7)$ & $67.8(7.6)$ & $64.4(7.5)$ \\
\hline \multirow[t]{3}{*}{ HRT at diagnosis } & No & $169(34.1)$ & $17(22.4)$ & $11(23.4)$ & $197(31.8)$ \\
\hline & Yes & $168(33.9)$ & $21(27.6)$ & $11(23.4)$ & $200(32.3)$ \\
\hline & Unknown & $159(32.0)$ & $38(50.0)$ & $25(53.2)$ & $222(35.9)$ \\
\hline \multirow[t]{3}{*}{ Menopausal status at diagnosis } & Premenopausal & $40(8.1)$ & $11(14.5)$ & $2(4.3)$ & $53(8.6)$ \\
\hline & Postmenopausal & $446(89.9)$ & $65(85.5)$ & $42(89.4)$ & $553(89.3)$ \\
\hline & Unknown & $10(2.0)$ & $0(0.0)$ & $3(6.4)$ & $13(2.1)$ \\
\hline \multirow[t]{4}{*}{ BMI at baseline } & $<20$ & $21(4.2)$ & $4(5.3)$ & $2(4.3)$ & $27(4.4)$ \\
\hline & $20-<25$ & $242(48.8)$ & $33(43.4)$ & $18(38.3)$ & $293(47.3)$ \\
\hline & $25-<30$ & $159(32.1)$ & $30(39.5)$ & $14(29.8)$ & $203(32.8)$ \\
\hline & $\geq 30$ & $74(14.9)$ & $9(11.8)$ & $13(27.7)$ & $96(15.5)$ \\
\hline \multirow[t]{4}{*}{ Detection mode (three categories) } & Non-symptomatic & $301(60.7)$ & $27(35.5)$ & $22(46.8)$ & $350(56.5)$ \\
\hline & Interval & $68(13.7)$ & $13(17.1)$ & $6(12.8)$ & $87(14.1)$ \\
\hline & Symptomatic & $122(24.6)$ & $36(47.4)$ & $19(40.4)$ & $177(28.6)$ \\
\hline & Unknown* & $5(1.0)$ & $0(0.0)$ & $0(0.0)$ & $5(0.8)$ \\
\hline \multirow{2}{*}{$\begin{array}{l}\text { Detection mode (symptomatic } \\
\text { including interval cancer) }\end{array}$} & Non-symptomatic & $301(60.7)$ & $27(35.5)$ & $22(46.8)$ & $350(56.5)$ \\
\hline & Symptomatic & 195 (39.3) & $49(64.5)$ & $25(53.2)$ & $269(43.5)$ \\
\hline \multirow[t]{3}{*}{ Breast density } & Fatty & $73(14.7)$ & $7(9.2)$ & $13(27.7)$ & $93(15.0)$ \\
\hline & Moderate & $254(51.2)$ & $37(48.7)$ & $21(44.7)$ & $312(50.4)$ \\
\hline & Dense & $169(34.1)$ & $32(42.1)$ & $13(27.7)$ & $214(34.6)$ \\
\hline \multirow[t]{3}{*}{ Diagnostic period } & 1991-1996 & $62(12.5)$ & $21(27.6)$ & $11(23.4)$ & $94(15.2)$ \\
\hline & 1997-2001 & $173(34.9)$ & $28(36.8)$ & $19(40.4)$ & $220(35.6)$ \\
\hline & $2002-2007$ & $261(52.6)$ & $27(35.5)$ & $17(36.2)$ & 305 (49.3) \\
\hline
\end{tabular}

*Unknown if interval or symptomatic cancer.

Some methodological issues have to be considered. All Swedish residents are given a unique civil registration number at birth which facilitates record-linkage. The Swedish Cause of Death Registry offers complete data with a coverage of $97.3 \%$ in 2008 [32] and the cause of death for malignant tumours has been shown to be correct in $90 \%$ of cases [33]. Hence, information on cause of death in the present study is expected to have a high completeness and correctness.

Breast density in this study was estimated qualitatively by several radiologists. Both qualitative and quantitative methods of measuring mammographic density have shown an association between density and breast cancer risk [1]. Quantitative measurements are thought to be more exact and reliable [34]. However, there is no consensus which quantitative measure of breast density to use [35], which is why we consider it relevant to use a readily available qualitative mode of assessment such as a modified BI-RADS. Known determinants for breast density (BMI, HRT, age and menopausal status) were distributed as expected in relation to different categories of density in this study, indicating a valid measurement of breast density. No formal assessment of inter-observer variability was performed at the initial estimation of breast density in this study, which is a limitation. However, in a not yet published study, 1200 recent screening mammograms were prospectively doubleread by the same observers as in the present investigation. When applying the BIRADS classification with the modification described above, a kappa coefficient of 0.60 (0.55$0.65,95 \%$ confidence interval) and a quadratic weighted kappa of 0.66 (0.62-0.70, 95\% confidence interval) were found. This provides support of a substantial interobserver agreement between the radiologists.

There was a change from analogue to digital mammography at our institution in 2004. Difference in acquisition method has been reported not to be of great importance when using a qualitative density measure such as BIRADS [35].

BMI was used for adjustment as a potential confounder of the possibility to detect a tumour clinically or 
Table 2 Vital status, prognostic factors and treatment

\begin{tabular}{|c|c|c|c|c|c|}
\hline \multirow[t]{2}{*}{ Factor } & \multirow[t]{2}{*}{ Category } & Alive $(n=496)$ & Dead breast cancer $(n=76)$ & Dead other cause $(n=47)$ & \multirow[t]{2}{*}{ All $(n=619)$} \\
\hline & & \multicolumn{3}{|c|}{ Number (column percent) } & \\
\hline \multirow[t]{4}{*}{ Tumour size (mm) } & $\leq 10$ & $160(32.3)$ & $1(1.3)$ & $13(27.7)$ & $174(28.1)$ \\
\hline & $>10-\leq 20$ & $225(45.4)$ & $31(40.8)$ & $17(36.2)$ & $273(44.1)$ \\
\hline & $>20$ & $109(22.0)$ & $44(57.9)$ & $17(36.2)$ & $170(27.5)$ \\
\hline & Unknown & $2(0.4)$ & $0(0.0)$ & $0(0.0)$ & $2(0.3)$ \\
\hline \multirow[t]{3}{*}{ Axillary lymph node status (ALNI) } & Negative & $371(74.8)$ & $28(36.8)$ & $37(78.7)$ & $436(70.4)$ \\
\hline & Positive & $124(25.0)$ & $48(63.2)$ & $10(21.3)$ & $182(29.4)$ \\
\hline & Unknown & $1(0.2)$ & $0(0.0)$ & $0(0.0)$ & $1(0.2)$ \\
\hline \multirow[t]{4}{*}{ Nottingham grade } & । & $152(30.6)$ & $7(9.2)$ & $14(29.8)$ & $173(27.9)$ \\
\hline & $\|$ & $249(50.2)$ & $27(35.5)$ & $20(42.6)$ & $296(47.8)$ \\
\hline & III & $91(18.3)$ & $42(55.3)$ & $12(25.5)$ & $145(23.4)$ \\
\hline & Unknown & $4(0.8)$ & $0(0.0)$ & $1(2.1)$ & $5(0.8)$ \\
\hline \multirow[t]{3}{*}{ Estrogen receptor status (ER) } & Negative & $47(9.5)$ & $19(25.0)$ & $5(10.6)$ & $71(11.5)$ \\
\hline & Positive & $394(79.4)$ & $53(69.7)$ & $40(85.1)$ & $487(78.7)$ \\
\hline & Unknown & $55(11.1)$ & $4(5.3)$ & $2(4.3)$ & $61(9.9)$ \\
\hline \multirow[t]{3}{*}{ Progesterone receptor status (PgR) } & Negative & $182(36.7)$ & $44(57.9)$ & $26(55.3)$ & $252(40.7)$ \\
\hline & Positive & $201(40.5)$ & $22(28.9)$ & $14(29.8)$ & $237(38.3)$ \\
\hline & Unknown & $113(22.8)$ & $10(13.2)$ & $7(14.9)$ & $130(21.0)$ \\
\hline \multirow[t]{3}{*}{ Type of surgery } & Mastectomy & $182(36.7)$ & $48(63.2)$ & $19(40.4)$ & $249(40.2)$ \\
\hline & Sector-resection & $311(62.7)$ & $28(36.8)$ & $28(59.6)$ & $367(59.3)$ \\
\hline & Unknown & $3(0.6)$ & $0(0.0)$ & $0(0.0)$ & $3(0.5)$ \\
\hline \multirow[t]{5}{*}{ Axillary dissection } & No & $48(9.7)$ & $1(1.3)$ & $7(14.9)$ & $56(9.0)$ \\
\hline & Yes & $280(56.5)$ & $63(82.9)$ & $33(70.2)$ & $376(60.7)$ \\
\hline & Single node & $2(0.4)$ & $0(0.0)$ & $0(0.0)$ & $2(0.3)$ \\
\hline & Sentinel node & $162(32.7)$ & $11(14.5)$ & $6(12.8)$ & $179(28.9)$ \\
\hline & Unknown & $4(0.8)$ & $1(1.3)$ & $1(2.1)$ & $6(1.0)$ \\
\hline \multirow[t]{3}{*}{ Antihormonal treatment } & No & $245(49.4)$ & $33(43.4)$ & $28(59.6)$ & $306(49.4)$ \\
\hline & Yes & $242(48.8)$ & $42(55.3)$ & $19(40.4)$ & $303(48.9)$ \\
\hline & Unknown & $9(1.8)$ & $1(1.3)$ & $0(0.0)$ & $10(1.6)$ \\
\hline \multirow[t]{3}{*}{ Chemotherapy } & No & $380(76.6)$ & $51(67.1)$ & $42(89.4)$ & $473(76.4)$ \\
\hline & Yes & $57(11.5)$ & $23(30.3)$ & $3(6.4)$ & $83(13.4)$ \\
\hline & Unknown & $59(11.9)$ & $2(2.6)$ & $2(4.3)$ & $63(10.2)$ \\
\hline \multirow[t]{3}{*}{ Radiotherapy } & No & $172(34.7)$ & $27(35.5)$ & $23(48.9)$ & $222(35.9)$ \\
\hline & Yes & $269(54.2)$ & $47(61.8)$ & $22(46.8)$ & $338(54.6)$ \\
\hline & Unknown & $55(11.1)$ & $2(2.6)$ & $2(4.3)$ & $59(9.5)$ \\
\hline
\end{tabular}

at screening mammography. It would have been more accurate to adjust for BMI at diagnosis but this information was not available. Weight changes over time cannot be excluded, which could have resulted in residual confounding. Weight gain and a consequent rise in BMI is probably the most likely change to occur with increasing age [36,37]. We believe this non-differential misclassification could have attenuated the effect seen among women with fatty breasts.
Women with dense breasts, participating in the general screening program in Malmö, were invited at 18 instead of 24 months intervals. This may explain why the interval cancers were only slightly more common among women with dense breasts, which would otherwise have been expected according to data from previous studies [38,39]. This weak association between interval cancers and high breast density could also have attenuated a potential adverse effect of density on survival in women with non-symptomatic 
Table 3 Potential determinants for breast density and tumour detection

\begin{tabular}{|c|c|c|c|c|c|}
\hline \multirow[t]{3}{*}{ Factor } & \multirow[t]{3}{*}{ Category } & \multicolumn{3}{|c|}{ Breast density } & \multirow[b]{3}{*}{ p-value ${ }^{* *}$} \\
\hline & & Fatty $(n=93)$ & Moderate $(n=312)$ & Dense $(n=214)$ & \\
\hline & & \multicolumn{3}{|c|}{ Number (column percent) Mean, SD in italics } & \\
\hline Age at baseline & Years & $60.1(7.1)$ & $56.8(6.8)$ & $55.1(6.7)$ & $<0.0001$ \\
\hline Age at diagnosis & Years & $67.4(7.3)$ & $65.2(7.1)$ & $62.0(7.6)$ & $<0.0001$ \\
\hline \multirow[t]{3}{*}{ HRT at diagnosis } & No & $25(26.9)$ & $126(40.4)$ & $46(21.5)$ & $<0.0001$ \\
\hline & Yes & $10(10.8)$ & $84(26.9)$ & $106(49.5)$ & \\
\hline & Unknown & $58(62.4)$ & $102(32.6)$ & $62(29.0)$ & \\
\hline \multirow[t]{3}{*}{ Menopausal status at diagnosis } & Premenopausal & $3(3.2)$ & $18(5.8)$ & $32(15.0)$ & 0.001 \\
\hline & Postmenopausal & $89(95.7)$ & $287(92.0)$ & $177(82.7)$ & \\
\hline & Unknown & $1(1.1)$ & $7(2.2)$ & $5(2.3)$ & \\
\hline \multirow[t]{4}{*}{ BMI at baseline } & $<20$ & $0(0.0)$ & $10(3.2)$ & $17(7.9)$ & $<0.0001$ \\
\hline & $20-<25$ & $29(31.2)$ & $135(43.3)$ & $129(60.3)$ & \\
\hline & $25-<30$ & $27(29.0)$ & $123(39.4)$ & $53(24.8)$ & \\
\hline & $\geq 30$ & $37(39.8)$ & $44(14.1)$ & $15(7.0)$ & \\
\hline \multirow[t]{4}{*}{ Detection mode (three categories) } & Non-symptomatic & $50(53.8)$ & $183(58.7)$ & $117(54.7)$ & 0.333 \\
\hline & Interval & $10(10.8)$ & $43(13.8)$ & $34(15.9)$ & \\
\hline & Symptomatic & $31(33.3)$ & $83(26.6)$ & $63(29.4)$ & \\
\hline & Unknown* & $2(2.2)$ & $3(1.0)$ & $0(0.0)$ & \\
\hline \multirow[t]{2}{*}{ Detection mode (symptomatic including interval cancers) } & Non-symptomatic & $50(53.8)$ & $183(58.7)$ & $117(54.7)$ & 0.559 \\
\hline & Symptomatic & $43(46.2)$ & $129(41.3)$ & $97(45.3)$ & \\
\hline
\end{tabular}

*Unknown if interval or symptomatic cancer.

${ }^{* *}$ Continuous variables analysed with ANOVA and categorical variables with the Chi-2 test

cancers. Indeed, the strongest effect of density was seen in symptomatic cases. Interval cancers, which might have been missed at screening due to a masking effect at mammography, were included in this group, although the results may also indicate an independent effect of density on survival. There is however a problem with small numbers of breast cancer deaths in the stratified analyses, resulting in wide confidence intervals and consequently poor precision, why the results must be interpreted with caution. However, our main result is not a difference between symptomatic and non-symptomatic women but instead an over-all association between breast density and survival.

The increased mortality seen among women with dense breasts could be explained by competing mortality from other causes than breast cancer in women with fatty breasts. This seems unlikely however, as fewer women died from other causes than from breast cancer, and women who died from other causes died at a higher age. Moreover, although fatty breasts were associated with an increased risk of death from other causes, after adjustments for age, BMI, HRT and diagnostic period, these results were considerably attenuated and not statistically significant. It is also necessary to consider potential effects of lead time but to completely adjust for lead time bias is a challenging task. We adjusted our results for age, tumour size, axillary lymph node involvement, grade, hormonereceptor status, use of $\mathrm{HRT}$ and BMI. All this factors are likely to be associated with lead time and we believe these adjustments would have diminished potential effects of lead time bias. We are however aware that there could be residual confounding regarding lead time, which may have influenced our results through earlier tumour detected in women with fatty breasts. If so, this would then have led to a spuriously better survival in women with fatty breasts.

It is well known that younger women with breast cancer tend to have more aggressive tumours and younger women tend to have denser breasts. However, the proportion of younger women in this cohort is relatively low; mean age at diagnosis was 64.4 years (SD 7.5). All analysis were adjusted for age, tumour size, axillary lymph node involvement, grade and hormone-receptor status, which we believe would have diminished potential confounding by more aggressive tumours in younger women.

Results from previous studies on breast density and breast cancer specific survival are difficult to compare due to differences in methodology. The present and three previous studies $[4,5,14]$ used different qualitative classifications of breast density. Two studies used quantitative estimation of density by a computer-assisted method but one of these studies included only 27 breast 
Table 4 Breast density and subsequent breast cancer mortality in relation to mode of detection

\begin{tabular}{|c|c|c|c|c|c|}
\hline & Rate of breast cancer deaths & $\mathrm{HR}^{1}$ & $\mathrm{HR}^{2}$ & $\mathrm{HR}^{3}$ & $\mathrm{HR}^{4}$ \\
\hline \multicolumn{6}{|l|}{ All } \\
\hline Fatty & 7 of 93 & 1.00 & 1.00 & 1.00 & 1.00 \\
\hline Moderate & 37 of 312 & $1.82(0.81-4.08)$ & $1.80(0.79-4.10)$ & $2.02(0.87-4.67)$ & $2.09(0.90-4.85)$ \\
\hline Dense & 32 of 214 & $1.92(0.85-4.35)$ & $2.24(0.97-5.13)$ & $2.56(1.07-6.11)$ & $2.63(1.10-6.30)$ \\
\hline$p$-value for trend & & 0.173 & 0.058 & 0.039 & 0.035 \\
\hline \multicolumn{6}{|l|}{ Non-symptomatic } \\
\hline Fatty & 3 of 50 & 1.00 & 1.00 & 1.00 & - \\
\hline Moderate & 13 of 183 & $1.37(0.39-4.81)$ & $1.30(0.36-4.76)$ & $1.40(0.38-5.17)$ & - \\
\hline Dense & 11 of 117 & $1.47(0.41-5.27)$ & $1.66(0.43-6.41)$ & $2.04(0.49-8.49)$ & - \\
\hline$p$-value for trend & & 0.586 & 0.427 & 0.293 & - \\
\hline \multicolumn{6}{|l|}{ Symptomatic } \\
\hline Fatty & 4 of 43 & 1.00 & 1.00 & 1.00 & - \\
\hline Moderate & 24 of 129 & $2.43(0.84-7.02)$ & $2.20(0.74-6.51)$ & $2.62(0.86-7.98)$ & - \\
\hline Dense & 21 of 97 & $2.33(0.80-6.80)$ & $2.71(0.91-8.06)$ & $3.40(1.06-10.90)$ & - \\
\hline$p$-value for trend & & 0.216 & 0.081 & 0.045 & - \\
\hline
\end{tabular}

$\mathrm{HR}^{1}$ : Crude.

$\mathrm{HR}^{2}$ : Adjusted for diagnostic age (continuous), tumour size $(\mathrm{mm}), \mathrm{ALNI}$, grade, ER PgR and diagnostic period.

$\mathrm{HR}^{3}$ Adjusted for same factors as $\mathrm{HR}^{2}$ but also for HRT at diagnosis, BMI at baseline (continuous) and diagnostic period.

$\mathrm{HR}^{4}$ : Adjusted for the same factors as $\mathrm{HR}^{3}$ but also for mode of detection (non-symptomatic or symptomatic).

cancer deaths [17]. In a recent study from Sweden, evaluating breast density quantitatively, comparing 1115 screening-detected breast cancers and 285 interval cancers in postmenopausal women, women with interval cancers had generally more aggressive tumour characteristics and worse 5 year survival, although these differences were most pronounced among women with non-dense breasts [40]. There are however several differences between their and our study. Firstly, the study by Eriksson and al. used quantitative, computer assisted measures of breast density while we estimated breast density qualitatively. Secondly, symptomatic women not diagnosed as interval cancers were excluded from the study by Eriksson et al. It was not possible to study interval cancer separately in our analysis due to small numbers, which would indeed have been interesting. Thirdly, the end point in the study by Eriksson et al. was 5 year breast cancer specific survival, while most women in our study had a considerably longer follow-up, median 7.8 years (0.5-19.1). The limited number of events in our study must also be considered although the number of events was not given in the study by Eriksson et al.

Table 5 Mode of detection and subsequent breast cancer mortality in relation to breast density

\begin{tabular}{|c|c|c|c|c|c|}
\hline & Rate of breast cancer deaths & $\mathrm{HR}^{1}$ & $\mathrm{HR}^{2}$ & $\mathrm{HR}^{3}$ & $\mathrm{HR}^{4}$ \\
\hline \multicolumn{6}{|l|}{ All } \\
\hline Non-symptomatic & 27 of 350 & 1.00 & 1.00 & 1.00 & 1.00 \\
\hline Symptomatic & 49 of 269 & $2.68(1.67-4.28)$ & $1.55(0.95-2.53)$ & $1.52(0.92-2.50)$ & $1.56(0.94-2.58)$ \\
\hline Freedmans\%* & & & 55.5 & 57.5 & 54.9 \\
\hline \multicolumn{6}{|l|}{ Fatty/moderate } \\
\hline Non-symptomatic & 16 of 233 & 1.00 & 1.00 & 1.00 & - \\
\hline Symptomatic & 28 of 172 & $2.63(1.42-4.87)$ & $1.48(0.76-2.88)$ & $1.54(0.79-3.02)$ & - \\
\hline \multicolumn{6}{|l|}{ Dense } \\
\hline Non-symptomatic & 11 of 117 & 1.00 & 1.00 & 1.00 & - \\
\hline Symptomatic & 21 of 97 & $2.63(1.26-5.47)$ & $1.71(0.75-3.90)$ & $1.63(0.68-3.91)$ & - \\
\hline
\end{tabular}

$\mathrm{HR}^{1}$ : Crude.

$H R^{2}$ : Adjusted for diagnostic age (continuous), tumour size ( $\left.\mathrm{mm}\right), \mathrm{ALNI}$, grade, ER, PgR and diagnostic period.

$\mathrm{HR}^{3}$ Adjusted for same factors as $\mathrm{HR}^{2}$ but also for BMI at baseline (continuous), HRT at diagnosis and diagnostic period.

$H R^{4}$ : Adjusted for the same factors as $\mathrm{HR}^{3}$ but also for breast density.

*Freedmans\% express to what extent covariates can explain the differences in mortality between non-symptomatic vs. symptomatic patients. 
Two investigations both used the BI-RADS classification of breast density in four categories $[15,16]$ but differed in size and design. Moreover, Chui et al. [5] estimated breast density at baseline in a screening program instead of at diagnosis, which may to some extent have attenuated their findings given potential changes in breast density over time. The results by Chiu et al., also based on a Swedish population, were similar to ours with an increased risk of breast cancer death in relation to density and with an even more increased risk in adjusted analyses. A problem in the majority of previous, and the present study, was the low number of included events, ranging from 26 [14] to 127 [5]. Despite a mean followup time of 7.8 years, the present study only included 76 events in the main analysis. On the other hand, the study by Gierach et al., based on data from the US Breast Cancer Surveillance Consortium, included 9232 women out of whom 889 died from breast cancer [16]. Their results showed no association between breast density and death from breast cancer. In that study nearly fifteen percent of women were treated with breast conserving surgery and not treated with radiotherapy, which most women in Sweden would have been. Women with BI-RADS category 1 were also to a lesser extent treated with chemotherapy than women in BI-RADS category 4, despite women with fatty breasts having more adverse tumour characteristics. Their results were indeed stratified for stage and adjusted for therapy but it could be that other population related differences, e.g. lack of population based mammography screening in the United States and differences regarding health care financing make results difficult to compare.

The mechanism underlying the association between breast density and breast cancer is not clear. Several studies have addressed the issue of an association between breast density and prognostic tumour characteristics but in most of these studies, no association or conflicting results have been seen between density and tumour size, ALNI or hormone receptor status [41]. Genetic factors could be of importance and there is evidence of common genetic polymorphisms related to both breast density and breast cancer development [42]. Apart from underlying genetics, breast density could biologically reflect hormonal factors $[12,43,44]$, and factors related to oxidative stress $[45,46]$, which could affect epithelial and/or stroma related processes [45-49]. It is possible to hypothesise that such factors could also influence breast cancer risk and/or outcome.

\section{Conclusions}

In conclusion, in this study, high breast density at diagnosis may be associated with a decreased breast cancer specific survival. This association appears to be stronger in women with symptomatic cancers.

\section{Additional file}

Additional file 1: Table S1. Breast density and subsequent death from other cause than BC in relation to mode of detection. Table S2. Mode of detection in relation to death from other cause than $\mathrm{BC}$ and breast density.

\section{Abbreviations}

HRT: Hormone replacement therapy; BMI: Body mass index; MDCS: Malmö diet and cancer study; SD: Standard deviation; ALNI: Axillary lymph node involvement; ER: Estrogene receptor; PgR: Progesterone receptor; BIRADS: Breast imaging reporting and data system; ANOVA: Analysis of variance; HR: Hazard ratio.

\section{Competing interests}

All of the authors declare no financial or nonfinancial competing interests.

\section{Authors' contributions}

ÅO contributed in data acquisition, analysed and interpreted the data and drafted the article. HS contributed in data acquisition on breast density, conception, design, analysis and interpretation of data and critically revised the article. SB performed tissue micro arrays and critically revised the article. SZ contributed in data acquisition on breast density, conception, design, analysis and interpretation of data and also critically revised the article. JM contributed to conception and design, analysis and interpretation of data and critically revised and drafted the article. All authors read and approved the final manuscript

\section{Acknowledgements}

The study was conducted within the Breast Cancer network at Lund University (BCLU) and was supported by grants from The Ernhold Lundström Foundation, The Einar and Inga Nilsson Foundation, The Malmö University Hospital Foundation for Cancer Research, The Anna Lisa and Sven-Eric Lundgrens Foundation, The Crafoord Foundation, The Malmö University Hospital Founds and Donations and The Mossfelt Foundation. None of the foundations influenced the design, interpretation of data or the content of the manuscript. We also express our gratitude to Professor Göran Landberg for contributing data.

\section{Author details}

${ }^{1}$ Department of Surgery, Lund University, Skåne University Hospital, SE- 205 02 Malmö, Sweden. Diagnostic Radiology, Lund University, Diagnostic Center for Imaging and Functional Medicine, Skåne University Hospital Malmö, Malmö, Sweden. ${ }^{3}$ Department of Oncology, Lund University, Skåne University Hospital, Lund, Sweden. ${ }^{4}$ Department of Plastic surgery, Lund University, Skåne University Hospital, Malmö, Sweden.

Received: 12 June 2013 Accepted: 10 March 2014

Published: 28 March 2014

\section{References}

1. McCormack VA, dos Santos SI: Breast density and parenchymal patterns as markers of breast cancer risk: a meta-analysis. Cancer Epidemiol Biomarkers Prev 2006, 15(6):1159-1169.

2. Buist DS, Porter PL, Lehman C, Taplin SH, White E: Factors contributing to mammography failure in women aged 40-49 years. J Natl Cancer Inst 2004, 96(19):1432-1440.

3. Carney PA, Miglioretti DL, Yankaskas BC, Kerlikowske K, Rosenberg R, Rutter CM, Geller BM, Abraham LA, Taplin SH, Dignan M, Cutter G, Ballard- Barbash R: Individual and combined effects of age, breast density, and hormone replacement therapy use on the accuracy of screening mammography. Ann Intern Med 2003, 138(3):168-175.

4. Olsen AH, Bihrmann K, Jensen MB, Vejborg I, Lynge E: Breast density and outcome of mammography screening: a cohort study. Br J Cancer 2009, 100(7):1205-1208.

5. Chiu SY, Duffy S, Yen AM, Tabar L, Smith RA, Chen HH: Effect of baseline breast density on breast cancer incidence, stage, mortality, and screening parameters: 25-year follow-up of a Swedish mammographic screening. Cancer Epidemiol Biomarkers Prev 2010, 19(5):1219-1228.

6. Li T, Sun L, Miller N, Nicklee T, Woo J, Hulse-Smith L, Tsao M-S, Khokha R, Martin L, Boyd N: The association of measured breast tissue 
characteristics with mammographic density and other risk factors for breast cancer. Cancer Epidemiol Biomarkers \&amp; prevention, Cancer Epidemiol biomarkers and prevention 2005, 14(2):343-349.

7. Boyd NF, Martin L, Bronskill M, Yaffe MJ, Duric N, Minkin S: Breast tissue composition and susceptibility to breast cancer. J Natl Cancer Inst 2010, 102(16):1224-1237

8. Vachon CM, Kuni CC, Anderson K, Anderson VE, Sellers TA: Association of mammographically defined percent breast density with epidemiologic risk factors for breast cancer (United States). Cancer Causes Control 2000, 11(7):653-662.

9. Tamimi RM, Hankinson SE, Colditz GA, Byrne C: Endogenous sex hormone levels and mammographic density among postmenopausal women. Cancer Epidemiol Biomarkers Prev 2005, 14(11 Pt 1):2641-2647.

10. Lam PB, Vacek PM, Geller BM, Muss HB: The association of increased weight, body mass index, and tissue density with the risk of breast carcinoma in Vermont. Cancer 2000, 89(2):369-375.

11. Vacek PM, Geller BM: A prospective study of breast cancer risk using routine mammographic breast density measurements. Cancer Epidemiol Biomarkers Prev 2004, 13(5):715-722

12. Greendale GA, Reboussin BA, Slone S, Wasilauskas C, Pike MC, Ursin G: Postmenopausal hormone therapy and change in mammographic density. J Natl Cancer Inst 2003, 95(1):30-37.

13. HoCP IARC (Ed): Breast Cancer Screening. Lyon(France); 2002.

14. van Gils CH, Otten JD, Verbeek AL, Hendriks JH, Holland R: Effect of mammographic breast density on breast cancer screening performance: a study in Nijmegen, The Netherlands. J Epidemiol Community Health 1998, 52(4):267-271

15. Porter GJ, Evans AJ, Cornford EJ, Burrell HC, James JJ, Lee AH, Chakrabarti J: Influence of mammographic parenchymal pattern in screening-detected and interval invasive breast cancers on pathologic features, mammographic features, and patient survival. AJR Am J Roentgenol 2007, 188(3):676-683.

16. Gierach GL, Ichikawa L, Kerlikowske K, Brinton LA, Farhat GN, Vacek PM Weaver DL, Schairer C, Taplin SH, Sherman ME: Relationship between mammographic density and breast cancer death in the Breast Cancer Surveillance Consortium. J Natl Cancer Inst 2012, 104(16):1218-1227.

17. Maskarinec G, Pagano IS, Little MA, Conroy SM, Park SY, Kolonel LN: Mammographic density as a predictor of breast cancer survival: the Multiethnic Cohort. Breast Cancer Res 2013, 15(1):R7.

18. Joensuu H, Lehtimaki T, Holli K, Elomaa L, Turpeenniemi-Hujanen T, Kataja V, Anttila A, Lundin M, Isola J, Lundin J: Risk for distant recurrence of breast cancer detected by mammography screening or other methods. JAMA 2004, 292(9):1064-1073.

19. Dawson SJ, Duffy SW, Blows FM, Driver KE, Provenzano E, LeQuesne J, Greenberg DC, Pharoah P, Caldas C, Wishart GC: Molecular characteristics of screen-detected vs symptomatic breast cancers and their impact on survival. Br J Cancer 2009, 101(8):1338-1344.

20. Wishart GC, Greenberg DC, Britton PD, Chou P, Brown CH, Purushotham AD, Duffy SW: Screen-detected vs symptomatic breast cancer: is improved survival due to stage migration alone? Br J Cancer 2008, 98(11):1741-1744.

21. Olsson A, Borgquist S, Butt S, Zackrisson S, Landberg G, Manjer J: Tumourrelated factors and prognosis in breast cancer detected by screening. Br J Surg 2012, 99(1):78-87.

22. Berglund G, Elmstahl S, Janzon L, Larsson SA: The Malmo diet and cancer study, design and feasibility. J Intern Med 1993, 233(1):45-51.

23. Manjer J, Carlsson S, Elmstahl S, Gullberg B, Janzon L, Lindstrom M, Mattisson I, Berglund G: The Malmo diet and cancer study: representativity, cancer incidence and mortality in participants and non-participants. Eur J Cancer Prev 2001, 10(6):489-499.

24. Zackrisson S: Non-attendance in breast cancer screening is associated with unfavourable socio-economic circumstances and advanced carcinoma. Int J Cancer 2004, 108:754-760.

25. Causes of death 2010. In National Board of Health and Welfare; 2011. www.socialstyrelsen.se/riktlinjer/nationellascreeningprogram/ brostcancer_screeningmedmammog.

26. World Health Organization. Histological typing of breast tumours. Second edition. Geneva, 1981. Ann Pathol 1982, 2:91-105.

27. Elston CW, EIO: Pathological prognostic factors in breast cancer. I. The value of histological grade in breast cancer: experience from a large study with long-term follow-up. Histopathology 1991, 19:403-410.
28. Borgquist S, Djerbi S, Ponten F, Anagnostaki L, Goldman M, Gaber A, Manjer J, Landberg $\mathrm{G}$, Jirstrom K: HMG-CoA reductase expression in breast cancer is associated with a less aggressive phenotype and influenced by anthropometric factors. Int J Cancer 2008, 123(5):1146-1153.

29. Jönsson P-E (Ed): Bröst Cancer. Astra Zeneca AB; 2009

30. American College of Radiology. www.acr.org.

31. Freedman LSGBI, Schatzkin A: Statistic validation of intermediate endpoints for chronic diseases. Stat Med 1992, 11:167-178.

32. Dödsorsaksstatisktik, Historik, produktionsmetoder och tillförlitlighet. In National Board of Health and Welfare; 2010. www.socialstyrelsen.se/ publikationer2011/2011-6-7

33. Johansson LA, Bjorkenstam C, Westerling R: Unexplained differences between hospital and mortality data indicated mistakes in death certification: an investigation of 1,094 deaths in Sweden during 1995. J Clin Epidemiol 2009, 62(11):1202-1209.

34. Yaffe MJ: Mammographic density. Measurement of mammographic density. Breast Cancer Res 2008, 10(3):209.

35. Harvey JA, Gard CC, Miglioretti DL, Yankaskas BC, Kerlikowske K, Buist DS, Geller BA, Onega TL: Reported mammographic density: film-screen versus digital acquisition. Radiology 2013, 266(3):752-758.

36. Demark-Wahnefried W, Campbell KL, Hayes SC: Weight management and its role in breast cancer rehabilitation. Cancer 2012, 118(8 Suppl):2277-2287.

37. Statistisk Årsbok. Statistiska Centralbyrån; 2012. www.scb.se/statistik/_publikationer/ OV0904_2012A01_BR_00_A01BR1201.pdf.

38. Mandelson MT, Oestreicher N, Porter PL, White D, Finder CA, Taplin SH, White $\mathrm{E}$ : Breast density as a predictor of mammographic detection: comparison of interval- and screen-detected cancers. J Natl Cancer Inst 2000, 92(13):1081-1087.

39. Ma L, Fishell E, Wright B, Hanna W, Allan S, Boyd NF: Case-control study of factors associated with failure to detect breast cancer by mammography. J Natl Cancer Inst 1992, 84(10):781-785.

40. Eriksson L, Czene K, Rosenberg LU, Tornberg S, Humphreys K, Hall P: Mammographic density and survival in interval breast cancers. Breast Cancer Res 2013, 15(3):R48.

41. Boyd NF, Martin LJ, Yaffe MJ, Minkin S: Mammographic density and breast cancer risk: current understanding and future prospects. Breast Cancer Res 2011, 13(6):223.

42. Varghese JS, Thompson DJ, Michailidou K, Lindstrom S, Turnbull C, Brown J, Leyland J, Warren RM, Luben RN, Loos RJ, Wareham NJ, Rommens J, Martin LJ, Vachon CM, Scott CG, Atkinson EJ, Couch FJ, Apicella C, Southey MC, Stone J, Li J, Eriksson L, Czene K, Boyd NF, Hall P, Hopper JL, Tamimi RM: Mammographic breast density and breast cancer: evidence of a shared genetic basis. Cancer Res 2012, 72(6):1478-1484.

43. Brisson J, Brisson B, Cote G, Maunsell E, Berube S, Robert J: Tamoxifen and mammographic breast densities. Cancer Epidemiol Biomarkers Prev 2000, 9(9):911-915.

44. Chow CK, Venzon D, Jones EC, Premkumar A, O'Shaughnessy J, Zujewski J: Effect of tamoxifen on mammographic density. Cancer Epidemiol Biomarkers Prev 2000, 9(9):917-921.

45. Martin LJ, Boyd NF: Mammographic density. Potential mechanisms of breast cancer risk associated with mammographic density: hypotheses based on epidemiological evidence. Breast Cancer Res 2008, 10(1):201.

46. Bhowmick NA, Neilson EG, Moses HL: Stromal fibroblasts in cancer initiation and progression. Nature 2004, 432(7015):332-337.

47. Alowami S, Troup S, Al-Haddad S, Kirkpatrick I, Watson PH: Mammographic density is related to stroma and stromal proteoglycan expression. Breast Cancer Res 2003, 5(5):R129-R135.

48. Guo YP, Martin $\sqcup$, Hanna W, Banerjee D, Miller N, Fishell E, Khokha R, Boyd NF: Growth factors and stromal matrix proteins associated with mammographic densities. Cancer Epidemiol Biomarkers Prev 2001, 10(3):243-248.

49. Wiseman BS, Werb Z: Stromal effects on mammary gland development and breast cancer. Science 2002, 296(5570):1046-1049.

doi:10.1186/1471-2407-14-229

Cite this article as: Olsson et al:: Breast density and mode of detection in relation to breast cancer specific survival: a cohort study. BMC Cancer 2014 14:229. 